\title{
Gustatory Salivation Is Associated with Body Mass Index, Daytime Sleepiness, and Snoring in Healthy Young Adults
}

\author{
Satoshi Izumi, ${ }^{1}$ Guang Hong, ${ }^{2}$ Koh Iwasaki, ${ }^{3}$ Masayuki Izumi, ${ }^{1}$ \\ Yusuke Matsuyama, ${ }^{4}$ Mirei Chiba, ${ }^{1}$ Takashi Toda ${ }^{1}$ and Tada-aki Kudo ${ }^{1}$ \\ ${ }^{1}$ Division of Oral Physiology, Tohoku University Graduate School of Dentistry, Sendai, Miyagi, Japan \\ ${ }^{2}$ Liaison Center for Innovative Dentistry, Tohoku University Graduate School of Dentistry, Sendai, Miyagi, Japan \\ ${ }^{3}$ Ishinomaki-Ogatsu Municipal Clinic, Ishinomaki, Miyagi, Japan \\ ${ }^{4}$ Department of International Community and Oral Health, Tohoku University Graduate School of Dentistry, \\ Sendai, Miyagi, Japan
}

\begin{abstract}
The taste detection system for oral fatty acid may be related to obesity. In addition, sleep is intrinsically and closely related to food intake and metabolism. However, the association of gustatory salivation with body mass index (BMI), daytime sleepiness, or sleep habits is largely unknown. Therefore, we evaluated the relationship between gustatory salivation and BMI, Epworth sleepiness scale (ESS, a daytime sleepiness scale) or sleep habits among 26 healthy young individuals (20 males and 6 females; mean age: $26.0 \pm 4.3$ years). We also measured the saliva flow rate (SFR) that was induced by gum-chewing or each of three prototypical tastants (acetic acid, sucrose, and $\mathrm{NaCl}$ ). Further, the SFR was induced by fatty acid, provided as oleic acid (OA) homogenized in non-fat milk. All participants showed normal rates of salivation during resting and gum-chewing states. The increase in the SFR induced by OA, but not by each of the three tastants, was associated with BMI. Moreover, both daytime sleepiness level and frequency of snoring were associated with the increase in the SFR induced by $\mathrm{NaCl}$. These results suggest that $\mathrm{BMI}$ is associated with salivation induced by oral fatty acid exposure. Additionally, the regulatory mechanism for the $\mathrm{NaCl}$ induced salivation reflex may have a relationship with impairments of the respiratory control system that are related to snoring during sleep and lead to daytime sleepiness because of insufficient sleep. Thus, measurement of gustatory salivation might contribute to the evaluation and prevention of obesity and sleeprelated breathing disorders.
\end{abstract}

Keywords: body mass index; Epworth sleepiness scale; fatty acid; gustatory salivation; sleep habit Tohoku J. Exp. Med., 2016 October, 240 (2), 153-165. C 2016 Tohoku University Medical Press

\section{Introduction}

The functions of sleep remain unclear in mammals. Nonetheless, sleep is regarded as playing a role in energy conservation and the recuperation of the nervous system, via reduced responsiveness during sleep (Siegel 2005; Brown et al. 2012; Shukla and Basheer 2016). Thus, sleep is intrinsically and closely associated with food intake and metabolism. In fact, feeding-induced satiety promotes both rapid eye movement (REM) sleep and non-REM sleep (Danguir and Nicolaidis 1979; Sinton et al. 1999). However, the associations of sleepiness, sleep habits, and body mass index (BMI) with salivation and other stomatognathic functions are largely unknown. In contrast, oral medicine (more specifically dental sleep medicine) has already been incorporated into and significantly contributed to the treatment of patients who are affected by some sleeprelated breathing disorders, such as obstructive sleep apnea.
For example, custom-made dental devices are used to reduce the index of apnea and hypopnea. This is known as oral appliance therapy (Clark et al. 2000; Hosoya et al. 2014; Bender 2016; Lavigne and Sessle 2016). At present, obstructive sleep apnea is principally believed to be associated with a narrowed upper airway (Dudley and Patel 2016; Kassim et al. 2016). Thus, clarifying the abovementioned associations would be important to the field of sleep medicine, especially in countries with relatively short sleeping times, such as Japan. The clarification of these associations could also contribute to the development of new, clinically applicable indicators for or treatments of sleep-related breathing disorders.

Obstructive sleep apnea is a subtype of sleep apnea syndrome and is marked by repetitive episodes of apnea and hypopnea during sleep. Obstructive sleep apnea additionally leads to daytime symptoms of functional impairment, such as impaired alertness (Young et al. 1993; Tanaka

Received August 26, 2016; revised and accepted September 23, 2016. Published online October 20, 2016; doi: 10.1620/tjem.240.153.

Correspondence: Tada-aki Kudo, Division of Oral Physiology, Tohoku University Graduate School of Dentistry, 4-1 Seiryo-machi, Aoba-ku, Sendai, Miyagi 980-8575, Japan.

e-mail: tkudo@m.tohoku.ac.jp 
and Shima 2010). Sleep apnea syndrome is associated with general health complications, including cardiovascular disease, hypertension, and diabetes mellitus, as well as oral complications, such as periodontitis (Elmasry et al. 2000; Peppard et al. 2000; Shahar et al. 2001; Tanigawa et al. 2004; Sales-Peres et al. 2016). The Epworth sleepiness scale (ESS) is a representative self-reported questionnaire that consists of 8 items for measuring human daytime sleepiness. It was developed by Johns in 1991, and is widely used as a convenient and inexpensive test to screen for sleep apnea syndrom by assessing subjective daytime sleepiness (Johns 1991; Tanigawa et al. 2005). Several previous studies have already investigated the relationships between oral status and ESS scores. For instance, a research group reported finding no association between the ESS score and periodontal status in morbidly obese patients (Sales-Peres et al. 2016). In addition, another group reported that patients with burning mouth syndrome, a chronic disease characterized by a burning sensation and pain in the oral cavity, exhibited significant decreases in the ESS score, as compared with a healthy control group (Lopez-Jornet et al. 2015). To the best of our knowledge, however, no research group has reported a study of the associations between the ESS score and the gustatory saliva reflex in human subjects.

Saliva is a mixture of secretory fluid from secretory glands in the oral cavity. Regarding salivation that is induced by taste stimulation, sour tastes increase the flow rate of whole saliva to a greater degree than do other prototypical taste qualities (i.e., salty, bitter, sweet, and umami tastes) (Hodson and Linden 2006; Sasano et al. 2010). Although individuals do not perceive the taste of dietary fat clearly, fat is nevertheless very tasty (Mizushige et al. 2007). The fatty acid taste refers to the taste of fatty acids such as oleic acid (OA), a monounsaturated fatty acid that has 18 carbon atoms and one double bond, and is found in many vegetable oils and animal oils. It has recently been suggested that, along with the 5 basic tastes, the fatty acid taste is also a prototypical taste. This suggestion is based on the identification of possible fatty-acid receptors, including fatty acid receptor 1 (FFAR1) that are present in taste bud cells of the tongue and the cells can activate taste nerves (Janssen and Depoortere 2013; Newman et al. 2013; DiPatrizio and Piomelli 2015). It is already known that FFAR1 is expressed in many endocrine cells, such as pancreatic beta cells, and is activated by long-chain (13-21 carbons) and medium-chain (6-21 carbons) fatty acids to mediate hormone secretion (Itoh et al. 2003; Edfalk et al. 2008; Janssen and Depoortere 2013).

Several studies have reported that OA detection thresholds differ across human individuals, and that there are inverse correlations between BMI and OA sensitivity (Stewart et al. 2010, 2011; Haryono et al. 2014; Asano et al. 2016). However, to the best of our knowledge, no research group has reported the existence of an enhanced saliva reflex that is induced by the administration of free fatty acid in the human oral cavity. It has also been unclear whether the flow rates of gustatory salivation induced by each tastant are associated with the BMI of healthy young individuals. Moreover, it is largely unknown how the extent of gustatory salivation induced by each tastant is related to sleepiness and various sleep habits. Therefore, in this study of healthy young adults, we investigated the association of gustatory salivation with BMI, as well as the relationships between gustatory salivation, ESS scores, and sleep habits.

\section{Materials and Methods}

Study outline

Subjects attending the laboratory at Tohoku University Graduate School of Dentistry completed a self-reported questionnaire on lifestyle habits (including daytime sleepiness and sleep habits) and the condition of their health. Each subject's weight, height, BMI, and fat rate were then measured using a bench-made stadiometer and a weight scale (Inner Scan 50; Tanita, Tokyo, Japan). Additionally, each subject's blood pressure was measured using an electronic sphygmomanometer (CH-550; Citizen, Tokyo, Japan). After these procedures, the attending subjects underwent the following tests: (1) tests of the increase in the saliva flow rate (SFR) that was induced in the first $1 \mathrm{~min}$ by various taste stimulations in the oral cavity (using acetic acid, sucrose, salt [ $\mathrm{NaCl}]$, and oleic acid), and (2) a test of the SFR for the first $5 \mathrm{~min}$ during resting or mastication, to evaluate the potential for salivation in each participant. In the study cohort of healthy young individuals, we subsequently evaluated (1) the association between the increases in the SFR induced by various taste qualities and BMI $\left(\mathrm{kg} / \mathrm{m}^{2}\right),(2)$ the relationships between the increases in the SFR induced by various taste qualities and daytime sleepiness, and (3) the association between the increases in the SFR induced by various taste qualities and several sleep habits. All experiments were performed in compliance with the Declaration of Helsinki (http:// www.wma.net) and institutional guidelines. Ethical approval for the study was obtained from the Ethics Committee of Tohoku University Graduate School of Dentistry. All subjects provided written informed consent and completed the study including questionnaire regarding sleep habits.

\section{Subjects}

The subjects were limited to non-medicated young adults (20 to 39 years of age) who were in good health at the time of testing and were normotensive non-smokers, based on the results of the examinations in the present study. The subjects were also limited to individuals who reached SFRs of $0.1 \mathrm{~mL} / \mathrm{min}$ and $1.0 \mathrm{~mL} / \mathrm{min}$ in the resting and gum-chewing states, respectively. Based on previous reports (Humphrey and Williamson 2001; Satoh-Kuriwada et al. 2014), these values were considered to be minimum flow rates for determining whether the candidates had normal salivation potential.

Thirty-six young adults were recruited as candidate subjects through public advertisements for the present study. However, ten candidate subjects were excluded from the analyses of the present study because they did not meet the abovementioned selection criteria. Therefore, the data of twenty-six ( $n=20$ male; $n=6$ female) adults (mean age: $26.0 \pm 4.3$ years; range: 20 to 38 ) were analyzed in the present study. Their BMIs ranged from 18.3 to $26.8 \mathrm{~kg} / \mathrm{m}^{2}$ (underweight $\left[\leq 18.5 \mathrm{~kg} / \mathrm{m}^{2}\right]: n=1$; normal weight $[\leq 18.5$ to $24.9 \mathrm{~kg} /$ $\left.\mathrm{m}^{2}\right]: n=24$; overweight [25 to $\left.29.9 \mathrm{~kg} / \mathrm{m}^{2}\right]: n=1$; obese $\left[30 \mathrm{~kg} / \mathrm{m}^{2}\right]: n$ 
$=0)$. The general characteristics of the study participants are summarized in Table 1.

\section{Determination of the increases in the SFR induced by three prototyp- ical tastants}

Sample water solutions for sour, sweet, and salty tastants were prepared using acetic acid, salt, and sucrose, respectively, at $160 \mathrm{mM}$. All of the tastants were purchased from Wako Pure Chemical Industries (Osaka, Japan). Subjects were presented with a set of each of the prototypical tastants. The subjects took $1 \mathrm{~mL}$ of each solution into their mouths. One min after tasting, the subjects then expelled the solution with the whole saliva secreted in the oral cavity from their mouths into a prepared conical collection tube. Using the stimulated whole saliva (SWS), the stimulated whole saliva flow rate (SWSFR) was then determined to evaluate the amount of early stage gustatory salivation, including peak salivary response. The mean time to reach peak salivary response to test stimuli is within $30 \mathrm{~s}$ for the basic tastes (Hodson and Linden 2006; Sasano et al. 2010; Sato et al. 2011). We considered it preferable to avoid excess stimulation of the oral cavity with tastants, to reduce the burden on the subjects and the hours that were necessary for their participation. To maintain the taste stimulation at a constant level, the subjects were requested not to expel or swallow whole saliva during the 1 min of monitoring.

Using unstimulated whole saliva (UWS), which refers to whole saliva secreted in the oral cavity during resting, the unstimulated whole saliva flow rate (UWSFR) was also measured to calculate the increases in the SFR that resulted from taste stimulation. In the present study, the increase in the SFR induced by each tastant was defined as the difference between the measured SFR during tasting (SWSFR) and that during resting (UWSFR). Subjects were asked to refrain from eating $2 \mathrm{~h}$ before testing. They were also requested to sit in an upright chair during the test and to rinse their mouths with distilled water between each taste sample.

\section{Determination of the increase in the SFR induced by $O A$}

$\mathrm{OA}$ is a fatty acid that is commonly found in the food supply and is easy to use because it is liquid at room temperature, even though it is poorly soluble in water (Haryono et al. 2014). Thus, the OA solution used in the present study consisted of an emulsion of food grade OA (Sigma-Aldrich, St. Louis, MO, USA) in non-fat milk (Morinaga Milk Industry, Tokyo, Japan) and was newly prepared for every session, following a previously established method (Stewart et al. 2010; Kulkarni and Mattes 2013; Haryono et al. 2014; Asano et al. 2016). OA was stored at $-20^{\circ} \mathrm{C}$ before use. To prepare OA samples, varying amount of $\mathrm{OA}$ and $12 \%(\mathrm{w} / \mathrm{v})$ powdered non-fat milk was added to beakers to achieve the desired final concentrations. Additionally, all preparations were mixed with $5 \%(\mathrm{w} / \mathrm{v})$ gum arabic (Acacia gum) (Wako Pure Chemical Industries) and liquid paraffin (Wako Pure Chemical Industries) to mask lubricity cues (Stewart et al. 2010; Haryono et al. 2014; Asano et al. 2016). To prevent oxidation of OA, all samples were mixed with $0.01 \%(\mathrm{w} / \mathrm{v})$ ethylenediaminetetraacetic acid (EDTA; Dojindo Laboratories, Kumamoto, Japan) as an antioxidant. Then, after adding distilled water, all additives in each beaker were homogenized for $12 \mathrm{~min}$ at $7000 \mathrm{rpm}$ with a homogenizer at room temperature (HM-310; As One, Tokyo, Japan), in order to prepare the OA emulsions. The vehicle was prepared in the same way. The amount of each additive for making all preparations was precisely measured each time using pipettes, a mass scale, and a measuring cylinder.
Subjects were presented with three different concentrations of OA solution: $0 \mathrm{mM}$ (control vehicle), $32 \mathrm{mM}$, and $160 \mathrm{mM}$. We used the same tasting and flow rate measurement procedures for OA as had been applied for the three prototypical tastants described above, with the singular exception that the tests of OA were conducted with the subjects wearing nose clips to minimize olfactory cues caused by volatilized OA.

\section{Determination of SFR during resting and mastication}

To evaluate the salivation potential of each participant in terms of an average SFR, the amount of salivation during resting and masticating states was measured for $5 \mathrm{~min}$. In the present study, we used a chewing gum that lacked both taste and odor for saliva extraction (Checkbuf salivary gum, Horiba, Kyoto, Japan) to determine the average SWSFR that was stimulated with mastication. Regardless of whether the resting or masticating state was being tested, the subjects were allowed to expel whole saliva from their mouths into a prepared conical collection tube at any point in time during the measurement period. Subjects were asked to refrain from eating $2 \mathrm{~h}$ before testing. They were also requested to sit in an upright chair during the test and to rinse their mouths with distilled water just before each test.

\section{Determination of the ESS score and degree of sleep habit}

In the present study, we calculated the ESS score based on a self-reported questionnaire in order to evaluate the degree of sleepiness that was felt by each participant. Briefly, the participants were asked to rate the likelihood of falling asleep by selecting the most appropriate of the following numbers: 0 , would never doze; 1 , slight chance of dozing; 2, moderate chance of dozing; 3, high chance of dozing. In the self-reported questionnaire, participants were asked about the likelihood that they would fall asleep during eight situations: (1) sitting and reading; (2) watching television; (3) sitting inactive in a public place; (4) as a passenger in a car for an hour without a break; (5) lying down to rest in the afternoon, when circumstances permit; (6) sitting and talking to someone; (7) sitting quietly after a lunch without alcohol; and (8) in a car, while stopped for a few minutes in the traffic. The ESS score is the sum of the 8 item-scores in the ESS. We adopted the ESS score of 10 as cut-off score for normal sleepiness. Scores strictly greater than 10 were regarded as indicating excessive sleepiness, in accordance with previous investigations (Johns 1991, 1994; Furuta et al. 1999; Hossain et al. 2005). The participants were also asked to rate certain sleep habits, detailed in Table 2 , on scales of 1 to 4 or 5 .

\section{Statistical analysis}

Sex differences in the participants' baseline characteristics (i.e., age, height, weight, BMI, body fat, and blood pressure) were assessed using Student's t-test. Differences in SFR between groups were assessed using one-way analysis of variance followed by Holm's test. Kendall's rank correlation coefficient was used to test for correlations among age, BMI, SFR, the increase in SFR that was stimulated by mastication or tasting, the ESS score, and the scores for sleep habits. In the correlation analyses, $P$-values were calculated for the hypothesis of no correlation. In each test, $P$-values $<0.05$ were considered statistically significant. Statistical analyses were performed using SPSS statistics, version 22.0 (IBM, Armonk, NY, USA), and the statistical package JSTAT for Windows, version 6.8. (Sato, Japan). 


\section{Results}

Each participant showed a SFR that was more than 0.1 $\mathrm{mL} / \mathrm{min}$ during the resting state (Table 1; Fig. 1A, B). No significant association was observed between the SFR during the resting state and age $(\tau=0.178, P>0.05)$ or BMI $(\tau$ $=0.091, P>0.05)$. Each participant also showed a SFR that was not less than $1.0 \mathrm{~mL} / \mathrm{min}$ during the masticating state (Fig. 1C, D). As was the case for the resting state, no significant association was observed between the SFR during the mastication state and age $(\tau=0.112, P>0.05)$ or BMI $(\tau=0.157, P>0.05)$.

As shown in Fig. 2 A to $G$, the increases in the SFR were measured for $1 \mathrm{~min}$ in each participant during tasting states, using the indicated concentrations of acetic acid, sucrose, $\mathrm{NaCl}$, and $\mathrm{OA}$ as tastant samples. BMI only showed significant associations with the increase in SFR for $32 \mathrm{mM} \mathrm{OA}$ and $160 \mathrm{mM} \mathrm{OA}(\tau=0.310, P<0.05$ and $\tau=$ $0.287, P<0.05$, respectively); no significant associations were observed with BMI for other tastants. We additionally evaluated the average SFR of all participants, which was significantly increased by the oral administration of 160 mM OA solution for $1 \mathrm{~min}$ (Fig. 2H).

The ESS score was specifically associated with the increase in the SFR induced by $160 \mathrm{mM} \mathrm{NaCl}(\tau=0.326, P$ $<0.05$ ), but not with any of the other investigated tastants (Fig. 3). No significant association was observed between the ESS score and age $(\tau=0.101, P>0.05)$ or BMI $(\tau=$ $-0.006, P>0.05)$. As shown in Fig. 4 , the increase in the SFR stimulated by $\mathrm{NaCl}$ was significantly associated with the frequency of snoring (question 6 in Table $2 ; \tau=0.458$, $P<0.01$ ), but not with any of the other investigated sleep habits (questions 1-6 in Table 2). The frequency of snoring was additionally associated with the increase in the SFR induced by $160 \mathrm{mM}$ sucrose $(\tau=0.481, P<0.01)$, but not with any of the other investigated tastants (Fig. 5). The ESS score was significantly associated with the frequency of unbearable drowsiness $(\tau=0.489, P<0.01)$, but not with the frequency of snoring (Fig. 6).

\section{Discussion}

In much of the world, there is an urgent need to reduce the rate of obesity that is associated with overeating. Indeed, obesity has important and adverse associations with various health complications and sleep-related breathing disorders. The present study is the first to characterize the modes of association between gustatory salivation and BMI, sleepiness, and various sleep habits in healthy young adults. The five prototypical tastes (sweet, sour, salty, bitter, and umami) are sensed by the taste $\mathrm{G}$ protein-coupled receptors (GPCRs) or channels expressed by taste-bud cells in the tongue (Niki et al. 2010; Janssen and Depoortere 2013). Moreover, humans could perceive some signals of the dietary fats that generally constitute the bulk of fats in foodstuffs (especially free fatty acids, but not triacylglycerides) via the following process; fatty acids are recognized chemically in tongue taste-bud cells that have putative fatty acid receptors. Subsequently, signals are transmitted to the brain through taste nerves (for instance, the glossopharyngeal nerves). Neuropeptides and neurotransmitters, such as

Table 1. Baseline characteristics of the participants*.

\begin{tabular}{|c|c|c|c|c|c|c|c|c|c|c|}
\hline & \multicolumn{3}{|c|}{ Men $(n=20)$} & \multicolumn{3}{|c|}{ Women $(n=6)$} & \multirow[b]{2}{*}{$P$-value** } & \multicolumn{3}{|c|}{ All $(n=26)$} \\
\hline & $n$ & Mean & $\mathrm{SD}$ & $n$ & Mean & SD & & $n$ & Mean & $\mathrm{SD}$ \\
\hline Age (years) & & 25.5 & 4.6 & & 27.3 & 2.5 & 0.243 & & 26.0 & 4.3 \\
\hline Height (cm) & & 172.9 & 0.05 & & 158.2 & 0.03 & $<0.001$ & & 169.5 & 0.08 \\
\hline Weight (kg) & & 64.5 & 6.5 & & 52.2 & 3.2 & 0.001 & & 61.7 & 7.9 \\
\hline BMI $\left(\mathrm{kg} / \mathrm{m}^{2}\right)$ & & 22.5 & 1.9 & & 20.9 & 1.9 & 0.441 & & 21.4 & 1.9 \\
\hline BMI range $\left(\mathrm{kg} / \mathrm{m}^{2}\right)$ & & $18.3-26.8$ & & & $19.2-24.2$ & & & & $18.3-26.8$ & \\
\hline Underweight $(n)$ & 1 & & & 0 & & & & 1 & & \\
\hline Normal weight $(n)$ & 18 & & & 6 & & & & 24 & & \\
\hline Overweight (n) & 1 & & & 0 & & & & 1 & & \\
\hline Obese $(n)$ & 0 & & & 0 & & & & 0 & & \\
\hline Body fat (\%) & & 16.2 & 3.5 & & 26.4 & 5.1 & $<0.001$ & & 18.6 & 5.0 \\
\hline SBP (mmHg) & & 121.6 & 9.6 & & 116.1 & 9.4 & 0.028 & & 114.8 & 5.6 \\
\hline DBP (mmHg) & & 69.9 & 4.6 & & 70.7 & 7.5 & 0.853 & & 70.0 & 9.2 \\
\hline UWSFR (mL/min) & & 0.8 & 0.4 & & 0.9 & 0.3 & 0.525 & & 0.8 & 0.3 \\
\hline SWSFR (mL/min) & & 2.3 & 0.8 & & 2.1 & 0.7 & 0.698 & & 2.2 & 0.8 \\
\hline UWSFR range (mL/min) & & $0.3-1.5$ & & & $0.6-1.2$ & & & & $0.3-1.5$ & \\
\hline SWSFR range (mL/min) & & $1.0-4.2$ & & & $1.1-2.8$ & & & & $1.0-4.2$ & \\
\hline
\end{tabular}

BMI, body mass index; SBP, systolic blood pressure; DBP, diastolic blood pressure,

UWSFR, unstimulated whole saliva flow rate; SWSFR, stimulated whole saliva flow rate.

*BMI: Underweight, $<18.5 \mathrm{~kg} / \mathrm{m}^{2}$; normal weight, $18.5-24.9 \mathrm{~kg} / \mathrm{m}^{2}$; overweight, $25-29.9 \mathrm{~kg} / \mathrm{m}^{2}$; obese, $\geq 30$

$\mathrm{kg} / \mathrm{m}^{2}$.

**Differences between men and women, as evaluated using Student's t-test.

Data are presented as the mean and standard deviation (SD). 
A

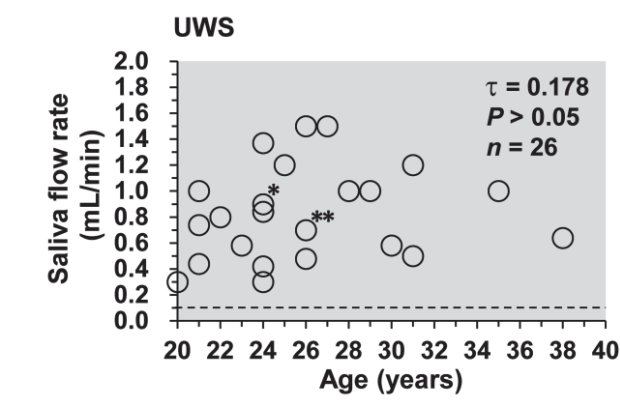

C

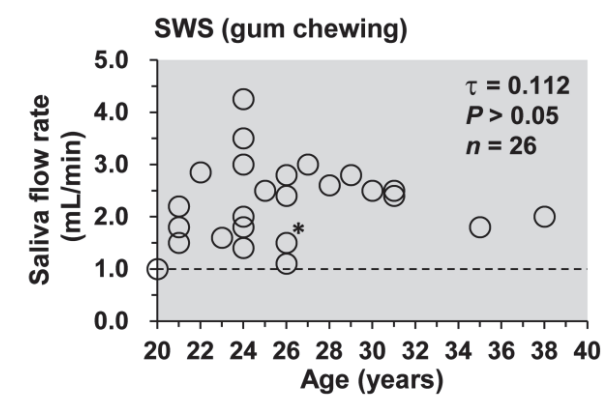

B

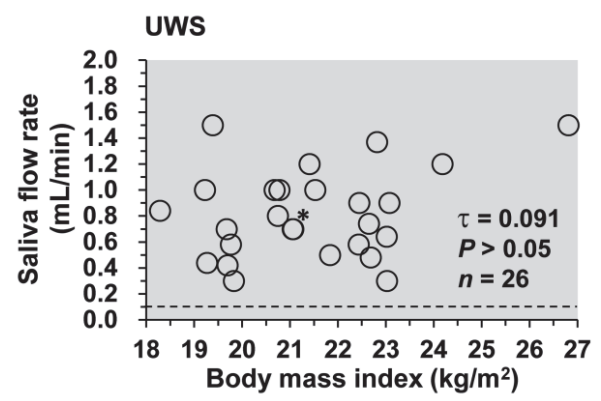

D

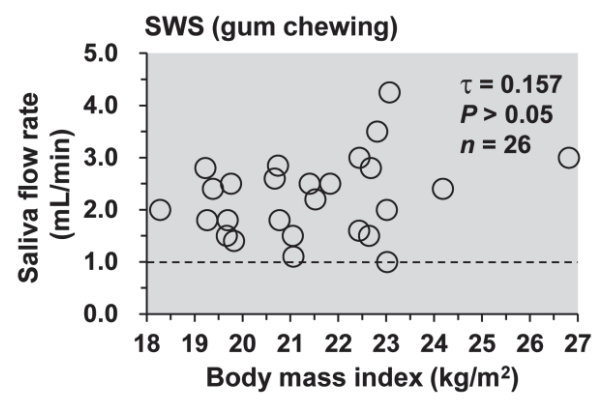

Fig. 1. Evaluation of salivation potential among the participants.

For each participant, the amount of secreted whole saliva was measured for 5 min during resting and masticating (gumchewing) states. (A, B) All participants showed normal rates of salivation during the resting state $(\geq 0.1 \mathrm{~mL} / \mathrm{min})$. No significant association was observed between the saliva flow rate during the resting state and age or body mass index (BMI). (C, D) All participants also showed normal rates of salivation during the masticating state ( $\geq 1.0 \mathrm{~mL} / \mathrm{min})$. No significant association was observed between the saliva flow rate during the gum-chewing state and age or BMI. Relationships were assessed using Kendall's rank correlation coefficient $(\tau)$. $P$-values are for the hypothesis of no correlation. Some of the plotted circles overlap closely or perfectly. Horizontal dashed lines show the cut-off values for decreased SFR during the resting and masticating states.

UWS, unstimulated whole saliva; SWS, stimulated whole saliva.

**Three plots are (almost) perfectly merged.

*Two plots are (almost) perfectly merged.

beta-endorphin and dopamine, are released shortly after fat intake (Fukuwatari et al. 1997; Hiraoka et al. 2003; Fushiki and Kawai 2005; Liang et al. 2006; Mizushige et al. 2006, 2007).

The notable clinical features of saliva include its ease of collection and non-invasive accessibility. Indeed, saliva is widely used for measuring the concentrations of hormones, cytokines, and other physiological active substances (Nie et al. 2014; Hiremath et al. 2015; Langie et al. 2016). Salivation in the oral cavity is induced as a neural reflex in the body. The quantity and type of secreted saliva are regulated by the autonomic nervous system (Edger 1992; Proctor and Carpenter 2014). Saliva glands receive dual innervation by both sympathetic and parasympathetic fibers, much like the other internal organs of the body. The neural reflex requires an afferent receptor, a nerve that conducts the impulse generated by stimulation, a reflex center (salivatory nucleus), and efferent pathways that include nerve bundles of sympathetic fiber or parasympathetic fiber, which innervate the saliva glands separately (Humphrey and Williamson 2001; Bradley et al. 2005). Despite the detailed understanding of saliva secretion, the relationships of the gustatory salivation mechanism with sleepiness and sleep habits have remained largely unknown, even in healthy individuals.

Based on the results from several large-scale studies of SFRs in healthy individuals, the general UWSFR and SWSFR is $0.3-0.4 \mathrm{~mL} / \mathrm{min}$ and $1.5-2.0 \mathrm{~mL} / \mathrm{min}$, respectively (Heintze et al. 1983; Dawes 1987). Both UWSFR and SWSFR differ greatly across individuals (Humphrey and Williamson 2001). Nonetheless, the presence of a UWSFR that is under $0.1 \mathrm{~mL} / \mathrm{min}$ during resting is accepted as objective evidence for impairment of the salivary secretion function in humans (Humphrey and Williamson 2001). Saliva is also secreted as a response to the mechanical stimulation of mastication and to stimulation by taste sensations, as shown in Figs. 1-3. The act of mastication stimulates salivation by itself if the object that is being masticated has no taste (Fig. 1) (Humphrey and Williamson 2001; Uneyama et al. 2009).

A SWSFR during gum-chewing of less than $1.0 \mathrm{~mL} /$ min was considered to indicate hyposalivation based on the proposal of the Research Committee on Sjögren's Syndrome of the Ministry of Health and Welfare in Japan 
A

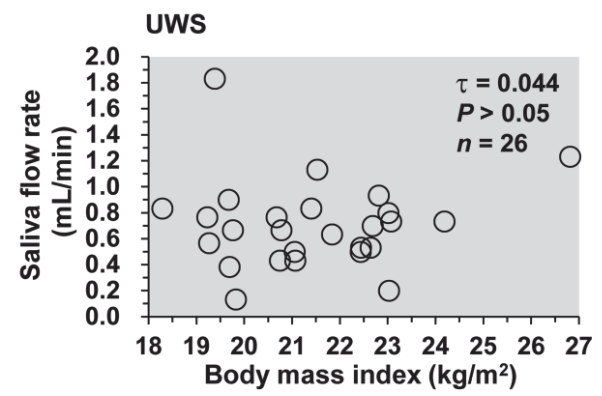

C

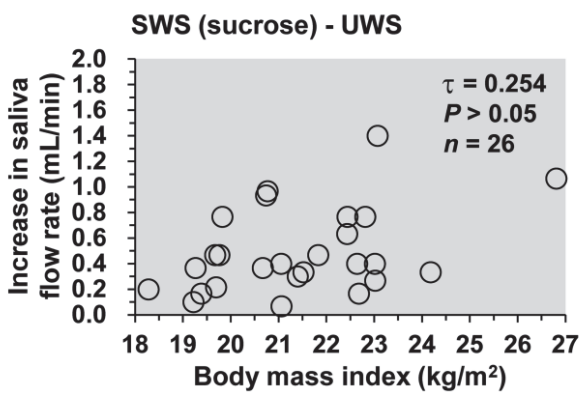

$\mathbf{E}$

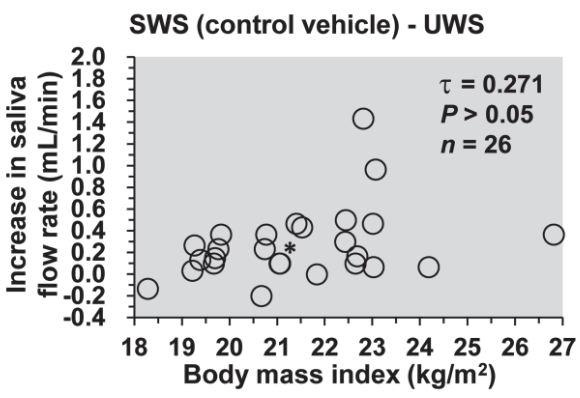

G

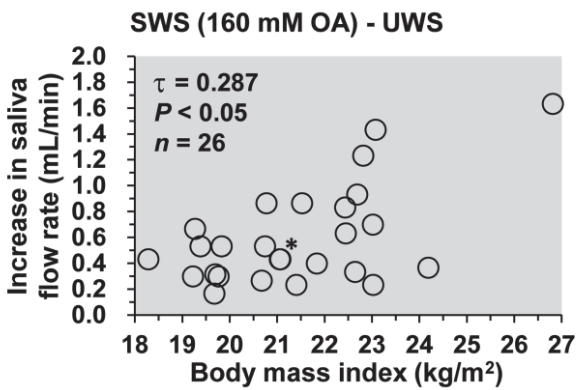

B

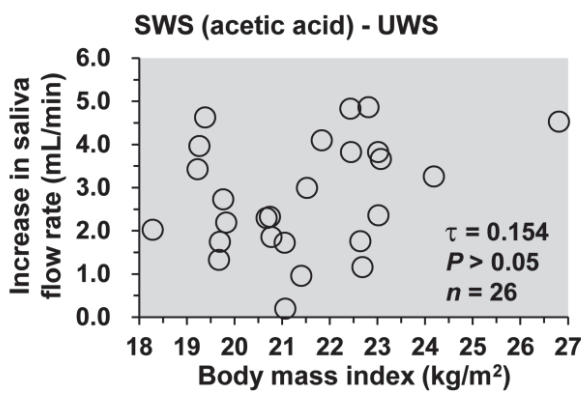

D

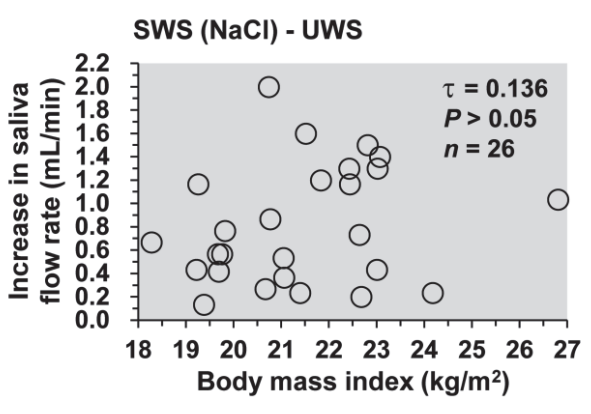

$\mathbf{F}$

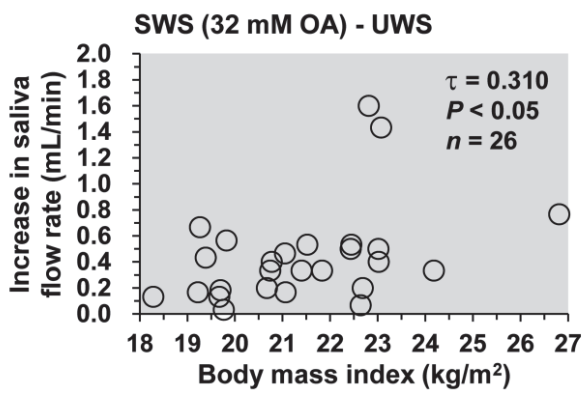

H

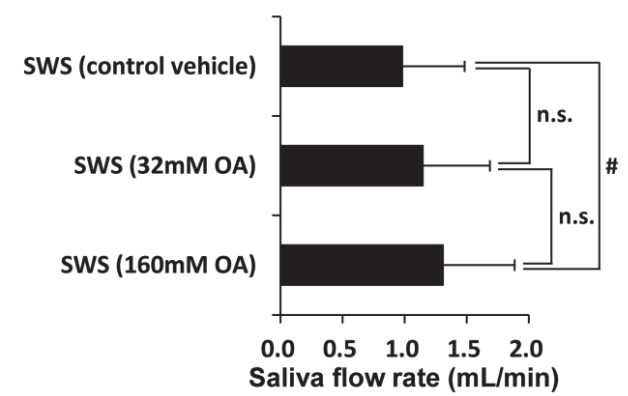

Fig. 2. The increase in SFR induced by OA is associated with BMI.

(A-G) For each participant, the amount of salivation during resting and tasting states was measured for 1 min using the indicated tastants. The increase in the saliva flow rate (SFR) induced by each tastant was calculated as the difference between the measured SFR during tasting and that during resting. Relationships were assessed using Kendall's rank correlation coefficient $(\tau)$. $P$-values are for the hypothesis of no correlation. Some of the plotted circles overlap closely or perfectly.

UWS, unstimulated whole saliva; SWS, stimulated whole saliva; OA, oleic acid.

*Two plots are (almost) perfectly merged.

(H) For each participant, the amount of salivation during resting and tasting states was measured for 1 min using the indicated tastants. The average SFR of all participants $(n=26)$ was significantly increased by the oral administration of OA solution during the first $1 \mathrm{~min}$.

Data are presented as the mean \pm standard deviation (SD).

$\# P<0.05$.

n.s., not significant. 
A

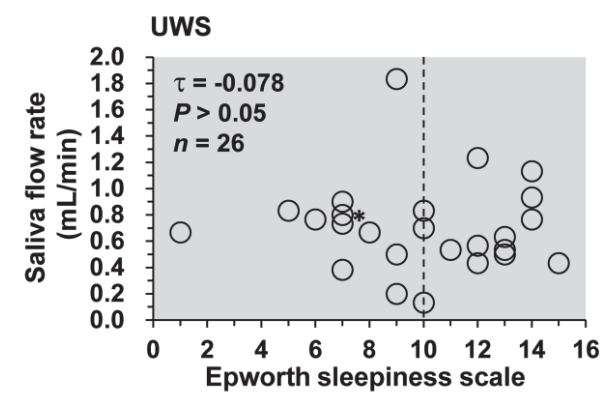

C

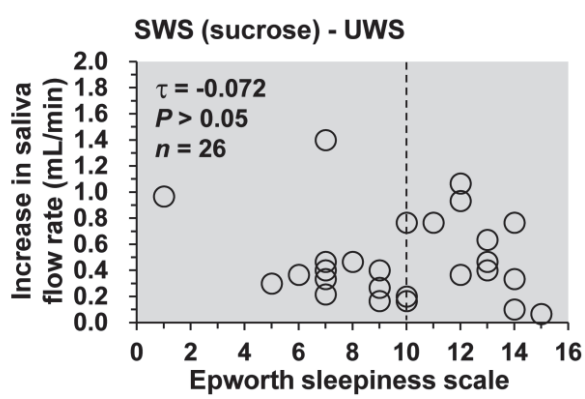

$\mathbf{E}$

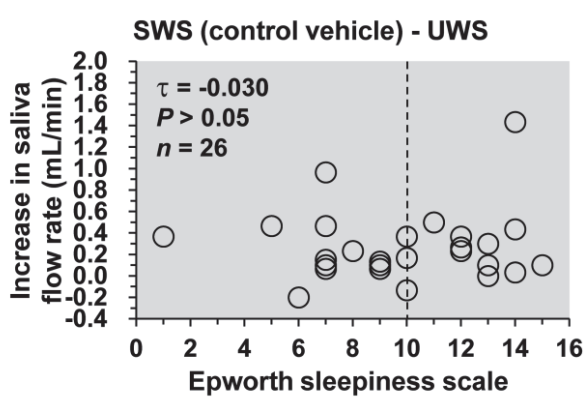

G

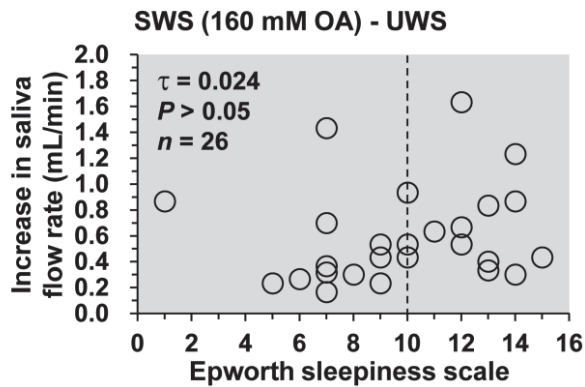

B

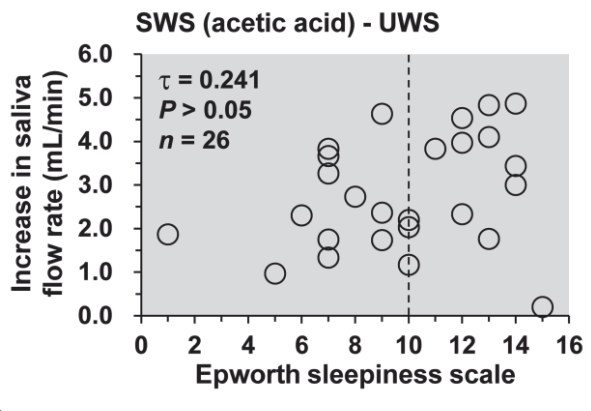

D

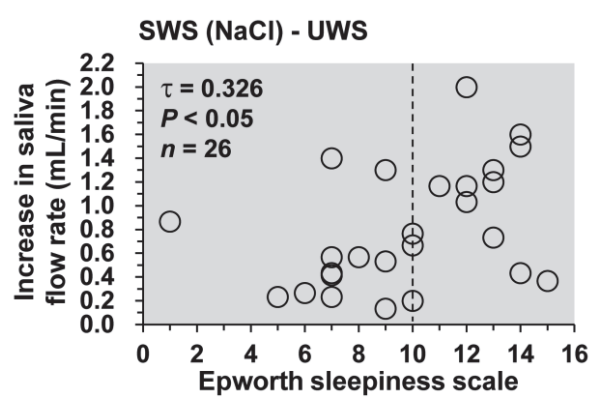

$\mathbf{F}$

SWS (32 mM OA) - UWS

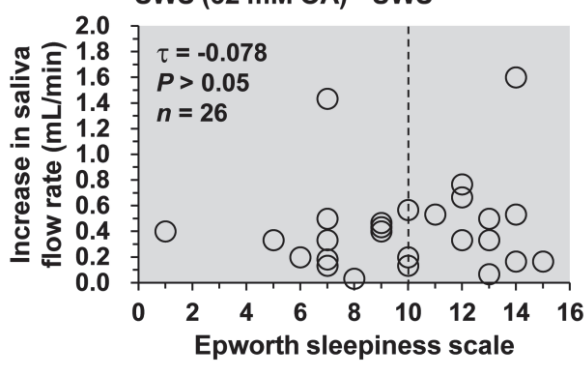

Fig. 3. The increase in SFR induced by $\mathrm{NaCl}$ is associated with the degree of daytime sleepiness.

For each participant, the amount of salivation was measured for 1 min during resting and tasting states using the indicated tastants. The increase in the saliva flow rate (SFR) induced by each tastant was calculated as the difference between the measured SFR during tasting and that during resting. Using the Epworth sleepiness scale (ESS), a self-reported questionnaire, the participants rated their likelihood of falling asleep ( 0 to 3 ) during 8 situations, as detailed in the Materials and Methods. The ESS score (the sum of the 8 item-scores in the ESS) of each participant were used for a subsequent correlation analysis. The ESS score was associated with the increase in SFR induced by $160 \mathrm{mM} \mathrm{NaCl}$. Relationships were assessed using Kendall's rank correlation coefficient $(\tau) . P$-values are for the hypothesis of no correlation. Some of the plotted circles overlap closely or perfectly. Vertical dashed lines show the cut-off score of 10, which has been established as identifying excessive daytime sleepiness.

UWS, unstimulated whole saliva; SWS, stimulated whole saliva; OA, oleic acid.

*Two plots are (almost) perfectly merged. 
A

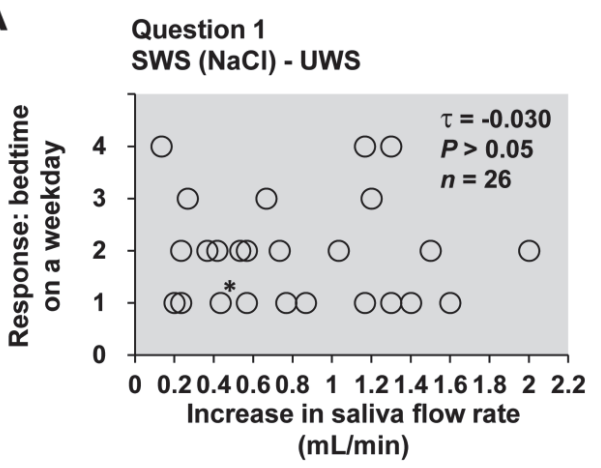

C

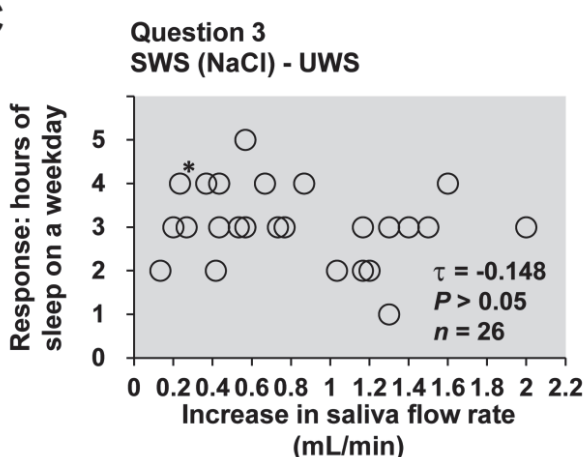

$\mathbf{E}$

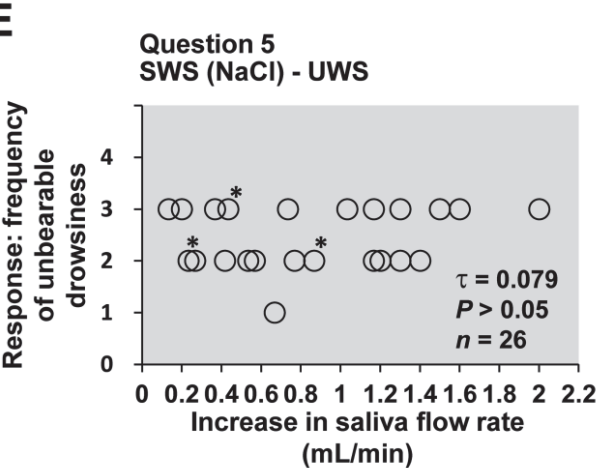

B
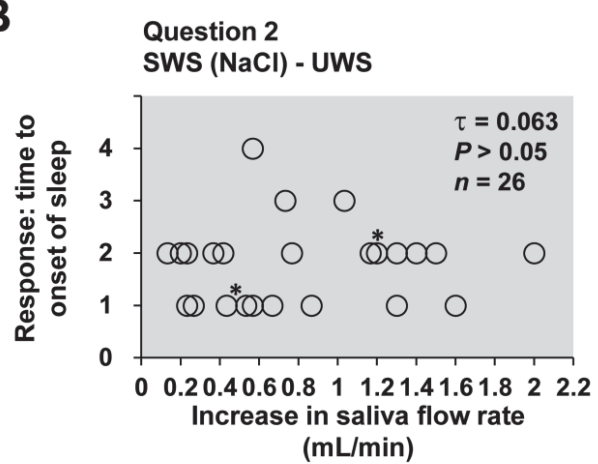

D

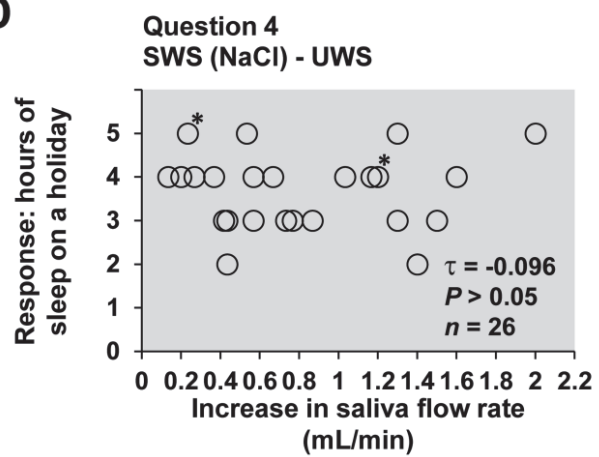

$\mathbf{F}$

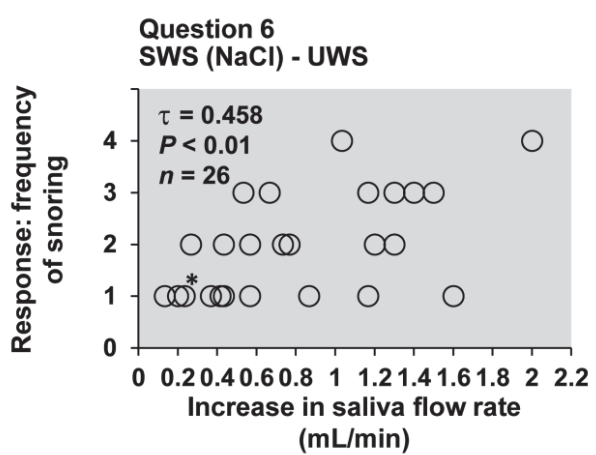

Fig. 4. The increase in SFR induced by $\mathrm{NaCl}$ is associated with the frequency of snoring.

For each participant, the amount of salivation was measured for 1 min during resting and NaCl-tasting states. The increase in the saliva flow rate (SFR) induced by $160 \mathrm{mM} \mathrm{NaCl}$ was calculated as the difference between the measured SFR during tasting and that during resting. In the self-reported questionnaire, the participants rated 6 indicated sleeping habits on a scale of 1 to 4 or 5 , as detailed in Table 2. The increase in the SFR stimulated by $\mathrm{NaCl}$ was significantly associated with the frequency of snoring (question 6 in Table 2), but not with any of the other investigated sleep habits (questions 1-5 in Table 2). Relationships were assessed using Kendall's rank correlation coefficient $(\tau)$. $P$-values are for the hypothesis of no correlation. All participants $(n=26)$ answered questions regarding sleep habits. Some of the plotted circles overlap closely or perfectly.

UWS, unstimulated whole saliva; SWS, stimulated whole saliva.

*Two plots are (almost) perfectly merged.

(Satoh-Kuriwada et al. 2014). Thus, in the present study, all participants had SFRs that were within the normal range during both the resting and masticating states (Table 1, Fig. 1 ); indeed, this was one of the requirements for participation in our study. The data that we acquired suggested that, at least among healthy young adults, age and BMI account for little or none of the inter-individual differences in resting and masticating SFRs.

Some studies have reported sex differences in salivation ability, which were suggested to result from differences in the sizes of salivary glands in men and women (Heintze et al. 1983; Inoue et al. 2006; Ono et al. 2007). However, in the present study, we observed no apparent differences between the SFRs of men and women during either the resting or masticating states, as shown in Table 1. Therefore, we decided to analyze the data for men and women together in the present study.

Regarding the relationship between taste-induced salivation and BMI, we found that BMI was significantly associated with increases in the SFR that were induced by 32 
Table 2. Questions on sleep habits from the self-reported questionnaire.

\begin{tabular}{|c|c|}
\hline Question 1. On average, what time do you go to bed on a weekday? & [Score $]$ \\
\hline Scale 1. Before midnight. & 1 \\
\hline Scale 2. From midnight to $1: 00 \mathrm{am}$. & 2 \\
\hline Scale 3. From 1:00 am to $2: 00 \mathrm{am}$. & 3 \\
\hline Scale 4. From 2:00 am to $3: 00 \mathrm{am}$. & 4 \\
\hline Scale 5. After 3:00 am. & 5 \\
\hline Question 2. How long does it take you to fall asleep after getting into bed? & [Score $]$ \\
\hline Scale 1. Less than 10 minutes. & 1 \\
\hline Scale 2. From 10 minutes to 30 minutes. & 2 \\
\hline Scale 3 . From 30 minutes to 1 hour. & 3 \\
\hline Scale 4. From 1 hour to 2 hours. & 4 \\
\hline Scale 5. More than 2 hours. & 5 \\
\hline Question 3. Please choose the average number of hours that you sleep on a weekday. & [Score $]$ \\
\hline Scale 1 . Less than 5 hours. & 1 \\
\hline Scale 2. From 5 hours to 6 hours. & 2 \\
\hline Scale 3. From 6 hours to 7 hours. & 3 \\
\hline Scale 4. From 7 hours to 8 hours. & 4 \\
\hline Scale 5. More than 8 hours. & 5 \\
\hline Question 4. Please choose the average number of hours that you sleep on a holiday. & [Score $]$ \\
\hline Scale 1. Less than 6 hours. & 1 \\
\hline Scale 2. From 6 hours to 7 hours. & 2 \\
\hline Scale 3. From 7 hours to 8 hours. & 3 \\
\hline Scale 4 . From 8 hours to 9 hours. & 4 \\
\hline Scale 5. More than 9 hours. & 5 \\
\hline Question 5. How often do you feel unbearable drowsiness during the daytime? & [Score $]$ \\
\hline Scale 1. I always feel unbearable drowsiness during the daytime. & 4 \\
\hline Scale 2. I sometimes feel unbearable drowsiness during the daytime. & 3 \\
\hline Scale 3. I infrequently feel unbearable drowsiness during the daytime. & 2 \\
\hline Scale 4. I never feel unbearable drowsiness during the daytime. & 1 \\
\hline Question 6. How often does someone tell you that you snore? & [Score $]$ \\
\hline Scale 1. Someone always tells me that I snore. & 4 \\
\hline Scale 2. Someone sometimes tells me that I snore. & 3 \\
\hline Scale 3. Someone infrequently tells me that I snore. & 2 \\
\hline Scale 4. Someone hardly ever tells me that I snore. & 1 \\
\hline
\end{tabular}

$\mathrm{mM} \mathrm{OA}$ and $160 \mathrm{mM} \mathrm{OA}$, but not with any other of the investigated tastants (Fig. 2A-G, Table 3). Accordingly, the oral OA detection systems that induce the saliva reflex may have specific relationships with and play essential roles in the initiation of efficient digestion for fat-containing, highcalorie foods in the gastrointestinal tract. This may occur via cephalic phase responses to taste perception (for instance, by enhancing gastric and pancreatic juice secretion via the autonomic nerve system) and may lead to higher BMI among healthy young adults. However, further multi-disciplinal investigation would be required to confirm this speculation.

In addition, it is noteworthy that the average SFR was significantly increased by a 1-min stimulation with $160 \mathrm{mM}$ OA that was administered to the oral cavity alone (Fig. 2H). This significant increase suggests the existence of a unique oral-OA-detection system that induces an oral OA-dependent immediate saliva reflex to assist with fatcontaining food digestion, at least during the oral phase of swallowing. To the best of our knowledge, we observed this phenomenon for the first time in human subjects. In contrast, the results of a previous study do not support the existence of fat-specific parotid saliva reflex (Hodson and Linden 2004). Their results appear to contradict our own, which may be attributable to differences between the two studies in terms of (i) the tastants that were used to increase the SFR and (ii) the methods of saliva collection. Indeed, Hodson and Linden (2004) used full-cream milk or cream cheese as tastants for oral fat stimulation, and measured only saliva that had been secreted from the parotid. These aspects of Hodson and Linden's materials and methods are different from our own. Although the molecular mechanisms of the oral OA-induced increases in SFR are largely unknown, they appear to be independent of the OA-detection system in the gastrointestinal tract. Note that the participants in the present study were asked not to swallow the OA samples after intake and, accordingly, no sample reached the gastrointestinal epithelium through the esophagus during our tests.

Regarding the relationships between taste-induced sal- 
A

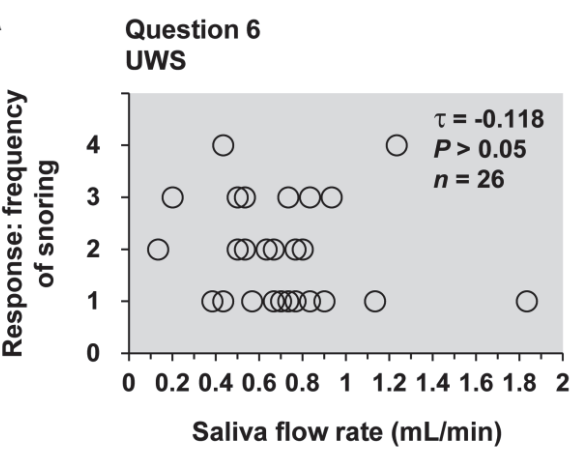

C

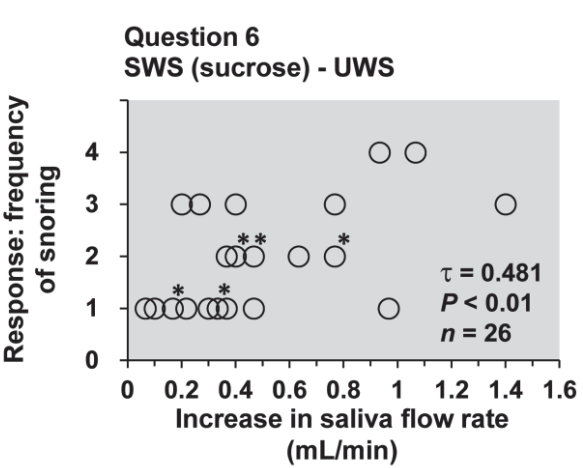

E

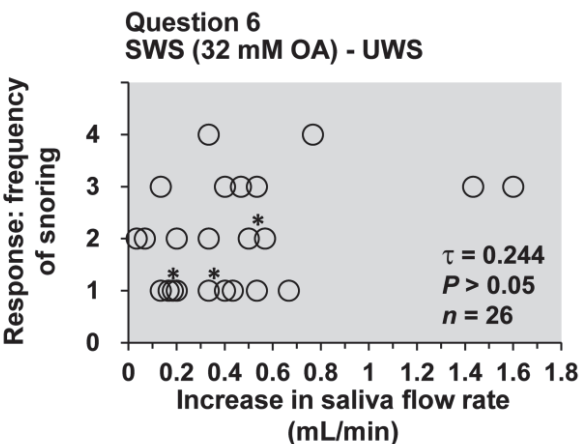

B

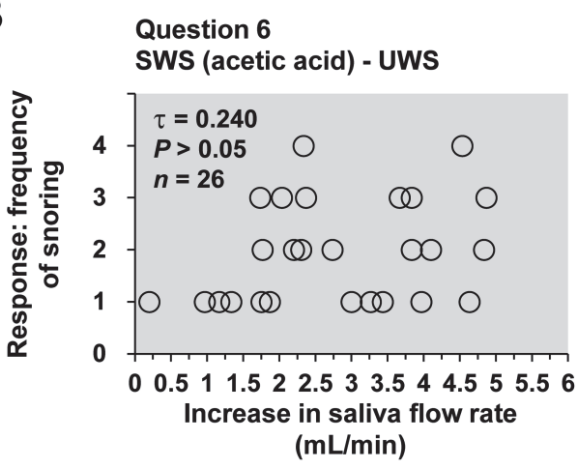

D
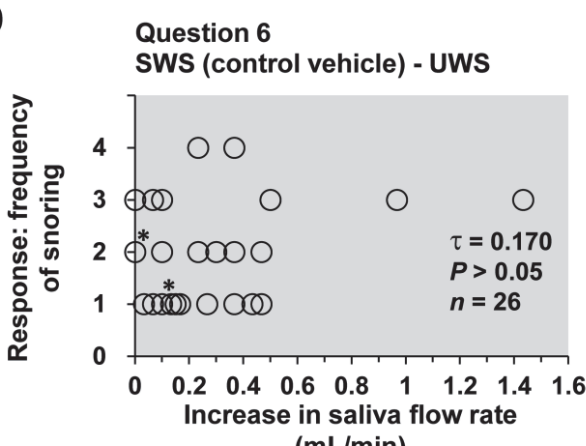

$(\mathrm{mL} / \mathrm{min})$

$\mathbf{F}$

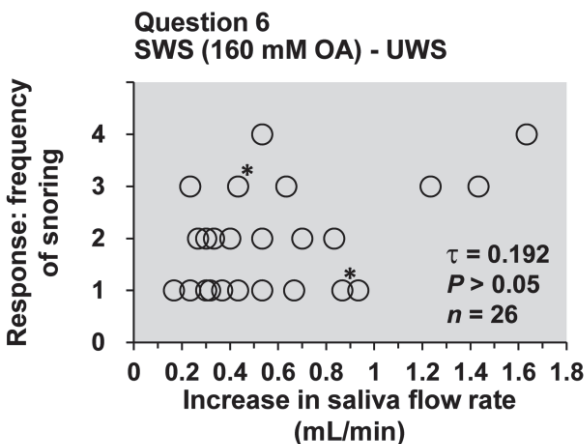

Fig. 5. The increase in SFR induced by sucrose is associated with the frequency of snoring.

For each participant, the amount of salivation was measured for 1 min during resting and various tasting states using the indicated tastants. The increase in the SFR induced by each tastant was calculated as the difference between the measured SFR during tasting and that during resting. In the self-reported questionnaire, the participants rated the frequency of snoring on a scale of 1 to 4 , as detailed in Table 2. The frequency of snoring (question 6 in Table 2) was significantly associated with the increase in SFR stimulated by $160 \mathrm{mM}$ sucrose, but not with the increases stimulated by the other investigated solutions (i.e., acetic acid, OA, and the control vehicle of OA). Relationships were assessed using Kendall's rank correlation coefficient $(\tau)$. $P$-values are for the hypothesis of no correlation. All participants $(n=26)$ answered questions regarding sleep habits. Some of the plotted circles overlap closely or perfectly.

UWS, unstimulated whole saliva; SWS, stimulated whole saliva; OA, oleic acid.

*Two plots are (almost) perfectly merged.

ivation, sleepiness, and sleep habits, our findings clearly demonstrated that the ESS score was associated with the increase in the SFR induced by $160 \mathrm{mM} \mathrm{NaCl}$, but not with age, BMI, or the other investigated tastants (Fig. 3, Table 3). These findings suggest that the oral $\mathrm{NaCl}$-detection system for the $\mathrm{NaCl}$-induced saliva reflex might have a specific relationship with some sleep habits or sleep-related breathing disorders that lead to sleepiness. Snoring is caused by the vibration of structures within the body, such as the soft plate, uvula, tonsils, base of tongue, epiglottis, and lateral pharyngeal walls (Dizdar et al. 2015). In subsequent analyses, we also found that the frequency of snoring was significantly associated with the increases in the SFR that were induced by $160 \mathrm{mM} \mathrm{NaCl}$ and $160 \mathrm{mM}$ sucrose, but not with the other investigated tastants (Figs. 4 and 5, Table 3). Obstructive sleep apnea is a subtype of sleep apnea syndrom that is principally associated with a narrowed upper airway that has resulted from fat accumulation accompanied with obesity or other congenital or acquired conditions (Dudley and Patel 2016; Kassim et al. 2016). Because 
A

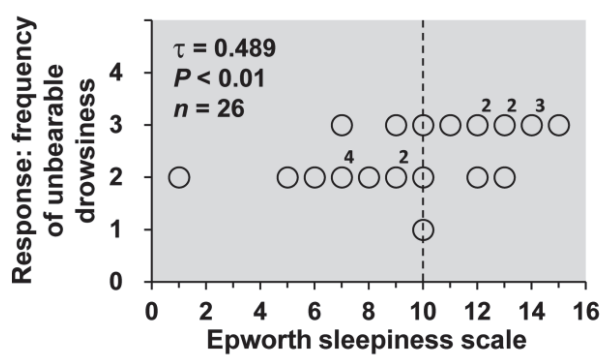

B

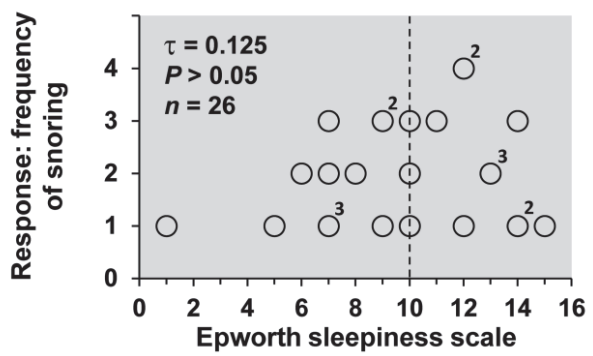

Fig. 6. Daytime sleepiness is associated with the frequency of drowsiness, but not with the frequency of snoring.

In the self-reported questionnaire, the participants rated the frequency of unbearable sleepiness and the frequency of snoring on a scale of 1 to 4, as detailed in Table 2. In addition, using the Epworth sleepiness scale (ESS), a self-reported questionnaire, the participants rated their likelihood of falling asleep (0 to 3$)$ during 8 situations, as detailed in the Materials and Methods. The ESS score (the sum of the 8 item-scores in the ESS) of each participant was used for the subsequent correlation analysis. The ESS score was significantly associated with the frequency of unbearable drowsiness (question 5 in Table 2), but not with the frequency of snoring (question 6 in Table 2). Relationships were assessed using Kendall's rank correlation coefficient $(\tau)$. $P$-values are for the hypothesis of no correlation. All participants $(\mathrm{n}=26)$ answered questions regarding sleep habits. Some of the plotted circles overlap closely or perfectly. The supplemental numbers (\#2 to \#4) located to the upper right of the plotted circles indicate the number of circles that share (almost) the same position. Circles that appear without supplemental numbers indicate single data points that do not overlap. Vertical dashed lines show the cut-off score of 10 , which has been established as identifying excessive daytime sleepiness.

Table 3. Summary of correlations between various gustatory salivation rates, BMI, ESS, and snoring habit.

\begin{tabular}{|c|c|c|c|c|c|c|}
\hline \multirow{2}{*}{$\begin{array}{l}\text { Taste samples used for } \\
\text { measuring SWSFR }\end{array}$} & \multicolumn{2}{|c|}{ BMI $\left(\mathrm{kg} / \mathrm{m}^{2}\right)^{*}$} & \multicolumn{2}{|c|}{ ESS score* } & \multicolumn{2}{|c|}{$\begin{array}{l}\text { Frequency of } \\
\text { Snoring* }\end{array}$} \\
\hline & $P$-value & $\tau$ & $P$-value & $\tau$ & $P$-value & $\tau$ \\
\hline $160 \mathrm{mM}$ acetic acid & $>0.05$ & 0.154 & $>0.05$ & 0.241 & $>0.05$ & 0.240 \\
\hline $160 \mathrm{mM}$ sucrose & $>0.05$ & 0.254 & $>0.05$ & -0.072 & $<0.01$ & 0.481 \\
\hline $160 \mathrm{mM} \mathrm{NaCl}$ & $>0.05$ & 0.136 & $<0.01$ & 0.326 & $<0.01$ & 0.458 \\
\hline $32 \mathrm{mM} \mathrm{OA}$ & $<0.05$ & 0.310 & $>0.05$ & -0.078 & $>0.05$ & 0.244 \\
\hline $160 \mathrm{mM} \mathrm{OA}$ & $<0.05$ & 0.287 & $>0.05$ & 0.024 & $>0.05$ & 0.192 \\
\hline
\end{tabular}

BMI, body mass index; ESS; Epworth sleepiness scale; OA, oleic acid; SWSFR, stimulated whole saliva flow rate.

Data summarize both the $P$-values for testing the hypothesis of no correlation and the coefficients of correlation $(\tau)$ shown in Figs. 2-5.

*Correlations were evaluated using Kendall's rank correlation coefficient.

snoring is an early and common symptom of obstructive sleep apnea, the abovementioned results suggest that part of the functional regulation system for the NaCl- or sucroseinduced saliva reflex might have an unknown relationship with a factor that affects or is affected by the status of upper airway, via unknown mechanisms. Interestingly, additional analyses in the present study revealed that the ESS score, which was used to assess daytime sleepiness, was associated with the degree of unbearable drowsiness, but not with the degree of snoring (Fig. 6). These findings providing supplemental support to the idea that the form of ESS used in this study performs well as an indicator of daytime sleepiness. In addition, our findings suggest that the ESS and degree of daytime sleepiness do not depend on the degree of snoring alone.

The following study limitations should be noted. The first limitation is the small sample size, which may have resulted in low statistical power, although it was sufficient to detect significant associations between gustatory salivation, BMI, sleepiness, and sleep habits. The second limitation is related to the self-report questionnaire. Because of the self-reported questionnaire, the potential for response bias must be taken into consideration when interpreting the results of our study in healthy young adults. It is also possible that some biases may have resulted from translation. Note that our research group originally prepared the questions in Table 2 and the rest of the self-report questionnaire in Japanese. The study participants received this Japanese version, rather than the translated version that is shown in the table. However, to evaluate daily sleepiness via ESS, we used a version of the ESS questionnaire that had previously been translated into Japanese and had been used in clinical settings in Japan. The version of the ESS questionnaire that we used for the present study is not the same as 
the validated Japanese version that was described in a previous report (Takegami et al. 2009). The third limitation is the application of many different tests with the same $P$-value threshold in our study (i.e., the multiple comparisons problem).

In summary, the present study firstly showed that BMI was associated with the increases in the SFR stimulated by $32 \mathrm{mM} \mathrm{OA}$ and $160 \mathrm{mM} \mathrm{OA}$, but not with those stimulated by $160 \mathrm{mM} \mathrm{NaCl}$ or other tastants. In contrast, ESS was associated with the increase in the SFR induced by $160 \mathrm{mM}$ $\mathrm{NaCl}$, but not with those induced by $160 \mathrm{mM}$ sucrose, 160 $\mathrm{mM}$ OA, or other tastants. Moreover, we found that the increases in the SFR induced by $160 \mathrm{mM}$ sucrose and 160 $\mathrm{mM} \mathrm{NaCl}$ were remarkably associated with degree of snoring habit, but did not show significant associations with any of the other investigated sleep habits. These results imply novel aspects of saliva's importance, which have never been described previously. They particularly suggest the following: First, BMI might affect or be affected by the flow rate of salivation induced by fatty acid taste stimulation, via some unknown mechanism. Second, some of the factors that regulate the $\mathrm{NaCl}$-induced gustatory salivation reflex may be related to or affected by processes that lead to impairment of respiratory control with habitual snoring during sleep. This, in turn, may induce daytime sleepiness because of insufficient sleep at night. The impairment could be caused by decreased ability to maintain an appropriate airway size in the upper airway, because of the formation of chronic edema around the neck. Additional research is needed on the hypothesized relationships that have been mentioned above. Nonetheless, it seems possible that the tastant-induced increases in the gustatory SFR could be useful, supplemental clinical indicators. The use of these indicators could deepen the current understanding of obesity, overweight, and complications related to insufficient durations of sleep, such as sleep apnea syndrome. These indicators could also help to classify obesity, overweight, and complications related to insufficient durations of sleep. Thus, it would be highly valuable to clarify the precise mechanisms that underlie the associations shown in the present study. Once available, such clarification could promote the development of novel, convenient, non-invasive, and objective saliva-based methods of evaluating and preventing obesity, overweight, and sleep-related breathing disorders.

\section{Acknowledgments}

We are grateful to Ms. Erika Ando, Ms. Emi Kanai, and Prof. Minoru Wakamori for advice, helpful discussion, and technical assistance on this work.

\section{Conflict to Interest}

The authors declare no conflict of interest.

\section{References}

Asano, M., Hong, G., Matsuyama, Y., Wang, W., Izumi, S., Izumi,
M., Toda, T. \& Kudo, T. (2016) Association of oral fat sensitivity with body mass index, taste preference, and eating habits in healthy Japanese young adults. Tohoku J. Exp. Med., 238, 93-103.

Bender, S.D. (2016) Sleep bruxism and sleep disordered breathing. J. Esthet. Restor. Dent., 28, 67-71.

Bradley, R.M., Fukami, H. \& Suwabe, T. (2005) Neurobiology of the gustatory-salivary reflex. Chem. Senses, 30 Suppl 1, i70-i71.

Brown, R.E., Basheer, R., McKenna, J.T., Strecker, R.E. \& McCarley, R.W. (2012) Control of sleep and wakefulness. Physiol. Rev., 92, 1087-1187.

Clark, G.T., Sohn, J.W. \& Hong, C.N. (2000) Treating obstructive sleep apnea and snoring: assessment of an anterior mandibular positioning device. J. Am. Dent. Assoc., 131, 765-771.

Danguir, J. \& Nicolaidis, S. (1979) Dependence of sleep on nutrients' availability. Physiol. Behav., 22, 735-740.

Dawes, C. (1987) Physiological factors affecting salivary flow rate, oral sugar clearance, and the sensation of dry mouth in man. J. Dent. Res., 66, 648-653.

DiPatrizio, N.V. \& Piomelli, D. (2015) Intestinal lipid-derived signals that sense dietary fat. J. Clin. Invest., 125, 891-898.

Dizdar, D., Civelek, Ş., Çaliş, Z.A., Dizdar, S.K., Coşkun, B.U. \& Vural, A. (2015) Comparative analysis of lateral pharyngoplasty and uvulopalatopharyngoplasty techniques with polisomnography and Epworth sleepiness scales. J. Craniofac. Surg., 26, e647-e651.

Dudley, K.A. \& Patel, S.R. (2016) Disparities and genetic risk factors in obstructive sleep apnea. Sleep Med., 18, 96-102.

Edfalk, S., Steneberg, P. \& Edlund, H. (2008) Gpr40 is expressed in enteroendocrine cells and mediates free fatty acid stimulation of incretin secretion. Diabetes, 57, 2280-2287.

Edger, W.M. (1992) Saliva: its secretion, composition and functions. Br. Dent. J., 172, 305-312.

Elmasry, A., Janson, C., Lindberg, E., Gislason, T., Tageldin, M.A. \& Boman, G. (2000) The role of habitual snoring and obesity in the development of diabetes: a 10-year follow-up study in a male population. J. Intern. Med., 248, 13-20.

Fukuwatari, T., Kawada, T., Tsuruta, M., Hiraoka, T., Iwanaga, T., Sugimoto, E. \& Fushiki, T. (1997) Expression of the putative membrane fatty acid transporter (FAT) in taste buds of the circumvallate papillae in rats. FEBS Lett., 414, 461-464.

Furuta, H., Kaneda, R., Kosaka, K., Arai, H., Sano, J. \& Koshino, Y. (1999) Epworth sleepiness scale and sleep studies in patients with obstructive sleep apnea syndrome. Psychiatry Clin. Neurosci., 53, 301-302.

Fushiki, T. \& Kawai, T. (2005) Chemical reception of fats in the oral cavity and the mechanism of addiction to dietary fat. Chem. Senses, 30 Suppl 1, i184-i185.

Haryono, R.Y., Sprajcer, M.A. \& Keast, R.S. (2014) Measuring oral fatty acid thresholds, fat perception, fatty food liking, and papillae density in humans. J. Vis. Exp., 88, e51236.

Heintze, U., Birkhed, D. \& Björn, H. (1983) Secretion rate and buffer effect of resting and stimulated whole saliva as a function of age and sex. Swed. Dent. J., 7, 227-238.

Hiraoka, T., Fukuwatari, T., Imaizumi, M. \& Fushiki, T. (2003) Effects of oral stimulation with fats on the cephalic phase of pancreatic enzyme secretion in esophagostomized rats. Physiol. Behav., 79, 713-717.

Hiremath, G., Olive, A., Shah, S., Davis, C.M., Shulman, R.J. \& Devaraj, S. (2015) Comparing methods to collect saliva from children to analyze cytokines related to allergic inflammation. Ann. Allergy Asthma Immunol., 114, 63-64.

Hodson, N.A. \& Linden, R.W. (2004) Is there a parotid-salivary reflex response to fat stimulation in humans? Physiol. Behav., 82, 805-813.

Hodson, N.A. \& Linden, R.W. (2006) The effect of monosodium glutamate on parotid salivary flow in comparison to the response to representatives of the other four basic tastes. 
Physiol. Behav., 89, 711-717.

Hosoya, H., Kitaura, H., Hashimoto, T., Ito, M., Kinbara, M., Deguchi, T., Irokawa, T., Obisa, N., Ogawa, H. \& TakanoYamamoto, T. (2014) Relationship between sleep bruxism and sleep respiratory events in patients with obstructive sleep apnea syndrome. Sleep Breath., 18, 837-844.

Hossain, J.L., Ahmad, P., Reinish, L.W., Kayumov, L., Hossain, N.K. \& Shapiro, C.M. (2005) Subjective fatigue and subjective sleepiness: two independent consequences of sleep disorders? J. Sleep Res., 14, 245-253.

Humphrey, S.P. \& Williamson, R.T. (2001) A review of saliva: Normal composition, flow, and function. J. Prosthet. Dent., 85, 162-169.

Itoh, Y., Kawamata, Y., Harada, M., Kobayashi, M., Fujii, R., Fukusumi, S., Ogi, K., Hosoya, M., Tanaka, Y., Uejima, H., Tanaka, H., Maruyama, M., Satoh, R., Okubo, S., Kizawa, H., et al. (2003) Free fatty acids regulate insulin secretion from pancreatic beta cells through GPR40. Nature, 422, 173-176.

Inoue, H., Ono, K., Masuda, W., Morimoto, Y., Tanaka, T., Yokota, M. \& Inenaga, K. (2006) Gender difference in unstimulated whole saliva flow rate and salivary gland sizes. Arch. Oral Biol., 51, 1055-1060.

Janssen, S. \& Depoortere, I. (2013) Nutrient sensing in the gut: new roads to therapeutics? Trends Endocrinol. Metab., 24, 92-100.

Johns, M.W. (1991) A new method for measuring daytime sleepiness: the Epworth sleepiness scale. Sleep, 14, 540-545.

Johns, M.W. (1994) Sleepiness in different situations measured by the Epworth sleepiness scale. Sleep, 17, 703-710.

Kassim, R., Harris, M.A., Leong, G.M. \& Heussler, H. (2016) Obstructive sleep apnoea in children with obesity. J. Paediatr. Child Health, 52, 284-290.

Kulkarni, B. \& Mattes, R. (2013) Evidence for presence of nonesterified fatty acids as potential gustatory signaling molecules in humans. Chem. Senses, 38, 119-127.

Langie, S., Szarc Vel Szic, K., Declerck, K., Traen, S., Koppen, G., Van Camp, G., Schoeters, G., Vanden Berghe, W. \& De Boever, P. (2016) Whole-genome saliva and blood DNA methylation profiling in individuals with a respiratory allergy. PLoS One, 11, e0151109.

Lavigne, G.J. \& Sessle, B.J. (2016) The neurobiology of orofacial pain and sleep and their interactions. J. Dent. Res., 95, 11091116.

Liang, N.C., Hajnal, A. \& Norgren, R. (2006) Sham feeding corn oil increases accumbens dopamine in the rat. Am. J. Physiol. Regul. Integr. Comp. Physiol., 291, R1236-R1239.

Lopez-Jornet, P., Lucero-Berdugo, M., Castillo-Felipe, C., Zamora Lavella, C., Ferrandez-Pujante, A. \& Pons-Fuster, A. (2015) Assessment of self-reported sleep disturbance and psychological status in patients with burning mouth syndrome. J. Eur. Acad. Dermatol. Venereol., 29, 1285-1290.

Mizushige, T., Matsumura, S., Yoneda, T., Tsuzuki, S., Inoue, K. \& Fushiki, T. (2006) Daily increase of fat ingestion mediated via mu-opioid receptor signaling pathway. Biomed. Res., 27, 259-263.

Mizushige, T., Inoue, K. \& Fushiki T. (2007) Why is fat so tasty? Chemical reception of fatty acid on the tongue. J. Nutr. Sci. Vitaminol., 53, 1-4.

Newman, L., Haryono, R. \& Keast, R. (2013) Functionality of fatty acid chemoreception: a potential factor in the development of obesity? Nutrients, 5, 1287-1300.

Nie, S., Henley, W.H., Miller, S.E., Zhang, H., Mayer, K.M., Dennis, P.J., Oblath, E.A., Alarie, J.P., Wu, Y., Oppenheim F.G., Little, F.F., Uluer, A.Z., Wang, P., Ramsey, J.M. \& Walt, D.R. (2014) An automated integrated platform for rapid and sensitive multiplexed protein profiling using human saliva samples. Lab Chip, 14, 1087-1098.

Niki, M., Yoshida, R., Takai, S. \& Ninomiya Y. (2010) Gustatory signaling in the periphery: detection, transmission, and modu- lation of taste information. Biol. Pharm. Bull., 33, 1772-1777.

Ono, K., Inoue, H., Masuda, W., Morimoto, Y., Tanaka, T., Yokota, M. \& Inenaga, K. (2007) Relationship of chewing-stimulated whole saliva flow rate and salivary gland size. Arch. Oral Biol., 52, 427-431.

Peppard, P.E., Young, T., Palta, M. \& Skatrud, J. (2000) Prospective study of the association between sleep-disordered breathing andhypertension. N. Engl. J. Med., 342, 1378-1384.

Proctor, G.B. \& Carpenter, G.H. (2014) Salivary secretion: mechanism and neural regulation. Monogr. Oral Sci., 24, 14-29.

Sales-Peres, S.H., Groppo, F.C., Rojas, L.V., Sales-Peres, M.C. \& Sales-Peres, A. (2016) Periodontal status in morbidly obese patients with and without obstructive sleep apnea syndrome risk: a cross-sectional study. J. Periodontol., 87, 772-782.

Sasano, T., Satoh-Kuriwada, S., Shoji, N., Sekine-Hayakawa, Y., Kawai, M. \& Uneyama, H. (2010) Application of umami taste stimulation to remedy hypogeusia based on reflex salivation. Biol. Pharm. Bull., 33, 1791-1795.

Sato, H., Obata, A.N., Moda, I., Ozaki, K., Yasuhara, T., Yamamoto, Y., Kiguchi, M., Maki, A., Kubota, K. \& Koizumi, H. (2011) Application of near-infrared spectroscopy to measurement of hemodynamic signals accompanying stimulated saliva secretion. J. Biomed. Opt., 16, 047002.

Satoh-Kuriwada, S., Kawai, M., Iikubo, M., Sekine-Hayakawa, Y., Shoji, N., Uneyama, H. \& Sasano, T. (2014) Development of an umami taste sensitivity test and its clinical use. PLoS One, 9, e95177.

Shahar, E., Whitney, C.W., Redline, S., Lee, E.T., Newman, A.B., Nieto, F.J., O'Connor, G.T., Boland, L.L., Schwartz, J.E. \& Samet, J.M. (2001) Sleep-disordered breathing and cardiovascular disease: cross-sectional results of the sleep heart health study. Am. J. Respir. Crit. Care Med., 163, 19-25.

Shukla, C. \& Basheer, R. (2016) Metabolic signals in sleep regulation: recent insights. Nat. Sci. Sleep, 8, 9-20.

Siegel, J.M. (2005) Clues to the functions of mammalian sleep. Nature, 437, 1264-1271.

Sinton, C.M., Fitch, T.E. \& Gershenfeld, H.K. (1999) The effects of leptin on REM sleep and slow wave delta in rats are reversed by food deprivation. J. Sleep Res., 8, 197-203.

Stewart, J.E., Feinle-Bisset, C., Golding, M., Delahunty, C., Clifton, P.M. \& Keast, R.S. (2010) Oral sensitivity to fatty acids, food consumption and BMI in human subjects. Br. $J$. Nutr., 104, 145-152.

Stewart, J.E., Newman, L.P. \& Keast, R.S. (2011) Oral sensitivity to oleic acid is associated with fat intake and body mass index. Clin. Nutr., 30, 838-844.

Takegami, M., Suzukamo, Y., Wakita, T., Noguchi, H., Chin, K., Kadotani, H., Inoue, Y., Oka, Y., Nakamura, T., Green, J., Johns, M.W. \& Fukuhara, S. (2009) Development of a Japanese version of the Epworth sleepiness scale (JESS) based on item response theory. Sleep Med., 10, 556-565.

Tanaka, S. \& Shima, M. (2010) Assessment of screening tests for sleep apnea syndrome in the workplace. J. Occup. Health, 52, 99-105.

Tanigawa, T., Tachibana, N., Yamagishi, K., Muraki, I., Kudo, M., Ohira, T., Kitamura, A., Sato, S., Shimamoto, T. \& Iso, H. (2004) Relationship between sleep-disordered breathing and blood pressure levels in community-based samples of Japanese men. Hypertens. Res., 27, 479-484.

Tanigawa, T., Horie, S., Sakurai, S. \& Iso, H. (2005) Screening for sleep-disordered breathing at workplaces. Ind. Health, 43, 53-57.

Uneyama, H., Kawai, M., Sekine-Hayakawa, Y. \& Torii, K. (2009) Contribution of umami taste substances in human salivation during meal. J. Med. Invest., 56 Suppl, 197-204.

Young, T., Palta, M., Dempsey, J., Skatrud, J., Weber, S. \& Badr, S. (1993) The occurrence of sleep-disordered breathing among middle-aged adults. N. Engl. J. Med., 328, 1230-1235. 